RESEARCH ARTICLE

\title{
Exploring the suitability of natural rubber and natural graphite for Mg rechargeable cells
}

\author{
R. Kasturiarachchi ${ }^{1}$, K.S. Perera ${ }^{1, *}$ and K.P. Vidanapathirana ${ }^{1}$ \\ ${ }^{1}$ Department of Electronics, Wayamba University of Sri Lanka, Kuliyapitiya, Sri Lanka
}

Received: 28/07/2018; Accepted: 22/10/2018

\begin{abstract}
Recently, the suitability of using natural rubber (NR) in place of expensive, toxic polymers to prepare polymer electrolytes has been suggested. So far, according to available reports, no attention has been given to employ Sri Lankan NR for this purpose. This study is based on optimization and characterization of a NR based electrolyte and evaluation its suitability for a $\mathrm{Mg}$ rechargeable cell. The optimized composition, 63 MG49 Natural Rubber : $\left.27 \mathrm{Mg}\left(\mathrm{CF}_{3} \mathrm{SO}_{3}\right)_{2}\right)$ : 10 EC (by weight basis) exhibits a conductivity of $2.83 \times 10^{-4} \mathrm{Scm}^{-1}$ at room temperature. The electrolyte is purely an ionic conductor having a negligible electronic conductivity. Rechargeable cells are fabricated with configuration, Mg / NR based electrolyte / natural graphite. Open circuit voltage of the cell is $1.5 \mathrm{~V}$ which may motivate the intention of researchers. The value is quite suitable for low power requirements. Electrochemical Impedance Spectroscopy as well as Cyclic Voltammetry tests prove the absence of any parasitic reactions in the cells. Constant load discharge test results confirm a discharge capacity of $5.32 \times 10^{-3} \mathrm{Ahg}^{-1}$. Results prove the candidacy of NR as well as graphite to be used for cells with several highlights.
\end{abstract}

Keywords: Natural Rubber, Magnesium cells, Natural graphite, Conductivity.

\section{INTRODUCTION}

Natural rubber (NR) is basically made from a milky white liquid called as latex. It comes from certain trees upon tapping. Though there are 200 species of trees that produce latex, 99\% of world's natural rubber is made from the latex obtained from the plant species, Hevea brasiliensis. It is commonly known as rubber tree. Latex is quickly oxidizing in air producing a very elastic, stretchy material. NR consists with the polymer known as polyisoprene (Borowski, Borowski, 2013).

Thailand, Indonesia, Malaysia and India are some of the biggest NR producers in the globe. Due to the remarkable features such as good processability, high tensile strength, satisfactory wear and tear resistance and excellent cold resistance, NR has found in many applications as an emerging class of material. With the rapid progression in the science and technology field, there is a new insight nowadays to prepare NR based electrolytes to employ in a diverse range of electrochemical devices. This has paved the way to employ NR as a substitute for commercially available polymers which are used to prepare solid polymer electrolytes. Due to the insulating nature of NR, various steps have been taken to alter the ionic conductivity and mechanical properties (Yusoff et al., 2015). With the soft elastomer characteristics of modified $\mathrm{NR}$, it is possible to make flat and flexible films so as to give good interfacial contacts between electrolytes and electrodes. Also, modified NR has lower glass transition temperatures promoting more amorphous phase which contributes immensely for segmental motion required for ion migration in polymer electrolytes. Epoxidizing and grafting polymethylmethacrylate (PMMA) are two modifications that have received a great attention (Low et al., 2010). Epoxidized NR is sticky and also very difficult to peel off from substrates (Noor et al., 2010). In PMMA grafted NR, methylmethacrylate (MMA) monomer is grafted to polyisoprene chain. Depending on the percentage of PMMA grafted on polyisoprene, those samples are labeled as MG 30, MG49 etc. MG 49 is having the highest percentage of PMMA (Ahmed et al., 2012). Methyl grafted (MG) NRs are found to be free standing, flexible and have good elasticity. As a result, they have motivated the attention of researchers' to be considered for serving as electrolytes in devices than epoxidized NRs (Gunasekaran et al., 2007; Khoon et al., 2016; Kamisan et al., 2009).

In Sri Lanka, NR is one of the main three export crops. Also, it is being used for few industries such as tire manufacturing and some other plastic goods production. But, it has not been exploited for any application in the field of energy and power. According to the literature, research activities carried out on NR are based on samples received from countries like Malaysia and India.Within Sri Lanka and also at international level, there is no any research report based on applicability of Sri Lankan NR for electrochemical applications. The present study was performed with the main objective of preparing and characterizing an electrolyte using Sri Lankan NR and applying it for a $\mathrm{Mg}$ rechargeable cell. Reason for designing a $\mathrm{Mg}$ rechargeable cell is to get rid from $\mathrm{Li}$ which has been well recognized as a harmful material. Another key feature in the present study is using Sri Lankan graphite electrode for the $\mathrm{Mg}$ cell. These approaches made it possible to showcase the feasibility of designing an environmental friendly, low cost cell. 


\section{METHODOLOGY}

\section{Preparation of electrolyte samples}

Methyl grafted natural rubber sample (MG49) was first cut into small pieces. They were allowed to swell and dissolved in toluene overnight. The solution was stirred magnetically for another 24 hours. Required amount of magnesium trifluoromethanesulfonate $\left(\mathrm{Mg}\left(\mathrm{CF}_{3} \mathrm{SO}_{3}\right)_{2}-\right.$ $\mathrm{MgTF}$ ) was dissolved in toluene and the two mixtures were mixed together by continuous stirring. Ethylene carbonate (EC) obtained from Aldrich was mixed to the (MG $49+$ MgTF) solution and further stirring was done. Resultant mixture was poured into a glass petri dish and allowed to evaporate the solvent slowly at room temperature. All the preparation steps were done under normal atmosphere at room temperature. Quantities of the starting materials were chosen according to the following equation.

\section{$X w t \%\left(x M G 49+x_{2} M g T F\right)+Y w t \% E C$}

where $X$ and $Y$ are variables (Yap et al., 2011). Samples were prepared varying $\mathrm{X}$ and $\mathrm{Y}$.

\section{Optimization of the composition}

A circular shape electrolyte sample was cut and sandwiched in between two well cleaned stainless steel (SS) electrodes inside a brass sample holder. Impedance measurements were gathered in the frequency range $16 \mathrm{MHz}$ to $10 \mathrm{mHZ}$ at room temperature. For this, a computer controlled Metrohm Impedance Analyzer was used. Procedure was repeated for all samples having different compositions.

\section{Conductivity variation with the temperature}

When the composition that results the highest room temperature conductivity was selected, impedance measurements were taken for that sample from room temperature to $55^{\circ} \mathrm{C}$.

\section{DC polarization test}

A circular shape electrolyte sample was assembled in between two SS electrodes in a sample holder as before. By applying a DC bias potential of $250 \mathrm{mV}$, the variation of the current through the cell was monitored.

\section{Fabrication of the cell, Mg / NR based electrolyte / \\ Graphite electrode}

Graphite electrode was prepared by mixing graphite: MgTF: polyvinylidenefluoride (PVdF) in acetone. Graphite was used as received from Bogala Graphite Lanka (Ltd), Sri Lanka without any purification.All materials were well mixed and spread on a SS dice as a thin film. Solvent was allowed to evaporate in air. $\mathrm{Mg}$ electrode was used as the other electrode. The cell having the configuration, $\mathrm{Mg} /$ NR electrolyte / graphite electrode was assembled inside a sample holder as shown in Figure 1.

\section{Study the performance of the cell}

Open circuit voltage $\left(\mathrm{V}_{\mathrm{OC}}\right)$ of the cell was measured using a digital multimeter. Impedance measurements were taken for the cell using a computer controlled Metrohm Impedance Analyser. Discharge characteristics were monitored for the cell under a constant load of $100 \mathrm{~K} \Omega$. Cyclability of the cell was observed using Cyclic Voltammetry (CV) technique. A three electrode electrochemical cell having $\mathrm{Mg}$ electrode as the counter and reference electrodes and graphite electrode as the working electrode was used for CV test. Readings were taken at the scan rate of $5 \mathrm{mVs}^{-1}$ in the potential window, $1.4 \mathrm{~V}-2.7 \mathrm{~V}$.

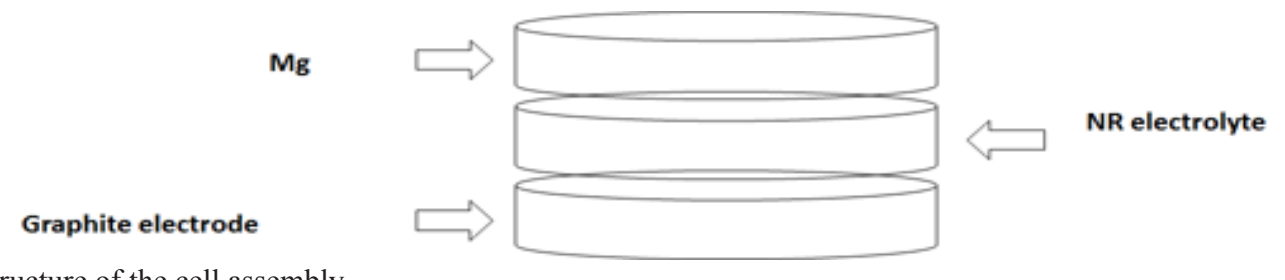

Figure 1: Structure of the cell assembly.

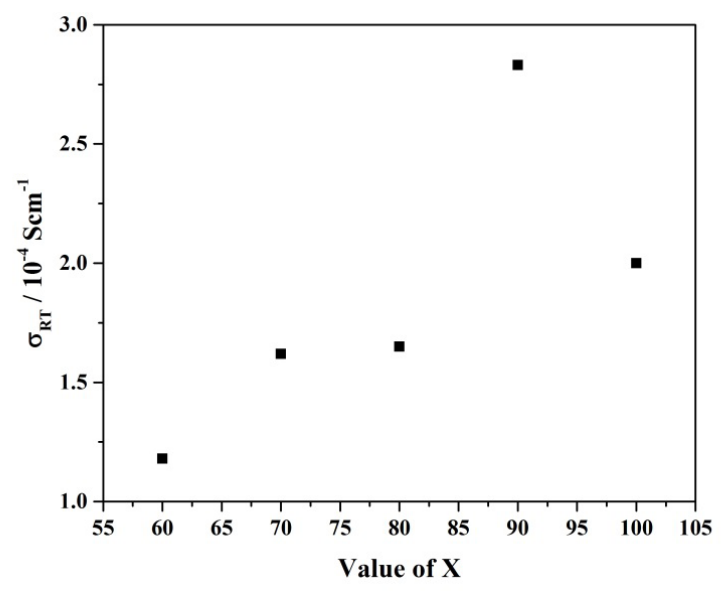

Figure2: Variation of room temperature conductivity $\left(\sigma_{\mathrm{RT}}\right)$ with $\mathrm{X}(\mathrm{X}=$ weight of NR and salt $)$. 


\section{RESULTS AND DISCUSSION}

\section{Optimized composition of the electrolyte}

Room temperature conductivity, $\left(\sigma_{\mathrm{RT}}\right)$ was calculated using the equation, $\sigma=\left(1 / R_{b}\right)(t / A)$ where $R_{b}$ is the bulk electrolyte resistance, $t$ is the thickness and $A$ is the area of cross section of the sample (Yusoff et al., 2015). Fig.2 shows the variation of room temperature conductivity with $\mathrm{X}$.

Initially, $\sigma_{\mathrm{RT}}$ increases with $\mathrm{X}$ and reaches a maximum followed by a decrease in Figure 2. The increasing trend of $\sigma_{\mathrm{RT}}$ can be due to the assistance given by MG49 for ion transport. Also, the increase of salt concentration may support for increase in $\sigma_{\mathrm{RT}}$. In general, $\sigma$ is governed by the charge carrier concentration $(n)$ and their mobility $(\mu)$ as

$$
\sigma=n e \mu
$$

where $e$ is the electron charge.

Charge carrier concentration and mobility may promote $\sigma_{\mathrm{RT}}$ (Yusoff et al., 2015, Ali et al., 2006). After the $\mathrm{X}$ value reaches 90, conductivity tends to reduce. At this region, salt concentration is high. The mean distance between ions then becomes a paramount importance for conductivity. It is because at high salt concentrations, number of charge carriers is high and so they become closer to each other. Thereby, they tend to form ion clusters which are in neutral state. Also, the number of transient crosslinks in the system may increase reducing chain mobility (Noor et al., 2010). This may result in lowering conductivity. In general, plasticizers like EC are famous for promoting ion conduction by weakening columbic forces between anions and cations of the salt (Ahmed et al., 2011). According to that, conductivity should increase with increase of EC. But, the results do not show such behavior. Effect of EC is not dominating. From the two competitive effects of MG49+ salt and EC, former may play a significant and effective role. The optimized composition was found as (63 MG49 : $\left.27 \mathrm{Mg}\left(\mathrm{CF}_{3} \mathrm{SO}_{4}\right)_{2}\right)$ : $10 \mathrm{EC}$ (by weight basis). It showed a conductivity of $2.83 \times 10^{-4} \mathrm{~S} \mathrm{~cm}^{-1}$. This value is very much suitable for employing the electrolyte in devices.

\section{Dependence of conductivity with temperature}

Figure 3 illustrates the dependence of conductivity on the temperature of the optimized composition.
From Figure 3, it is clearly seen that when the temperature increases, bulk electrolyte conductivity increases. With increasing temperature, ions become more energized and their mobility increases. As a result, conductivity increases according to the relationship,

$\sigma=n e \mu$ where $n$ is the ion concentration, $e$ is the charge and $\mu$ is their mobility. Another important feature of Fig. 2 is the presence of two regions for conductivity - temperature variation. There is a linear plot at high temperatures and a curved plot at low temperatures. The linear behavior at high temperatures suggests that conductivity mechanism follows Arrhenius behavior that can be given as,

$$
\dot{o}=\operatorname{Aexp}\left(-\mathrm{E}_{\mathrm{a}} / \mathrm{k}_{\mathrm{B}} \mathrm{T}\right)
$$

where $A$ is the pre exponential factor, $E_{a}$ is the activation energy, $k_{B}$ is the Boltzmann constant and $T$ is the absolute temperature (Khoon et al., 2016). This behavior is present when the ions jump or hop from one vacancy to another giving rise to conductivity.

Non linear or curve plots seen at low temperature regions are observed generally for highly viscous or amorphous polymer systems (Agnohorty et al., 2000). Under such situation, conductivity mechanism can be explained by Vogel Tamman Fulcher (VTF) equation given by,

$$
\sigma=A T^{-1 / 2} \exp \left(-E_{a} / k_{B}\left(T-T_{0}\right)\right) \text {. }
$$

Here, $A$ is the pre exponential factor, $E_{a}$ is the activation energy, $k_{B}$ is the Boltzmann constant and $T$ is the absolute temperature. It is believed that ion transport is taking place via polymer segmental motion and formation of free space when the conductivity mechanism follows VTF behavior.

With those observations, it is possible to conclude that at low temperatures, polymer chain is more flexible and it has a reasonable segmental motion which assists ionic motion greatly. But, as temperature rises, polymer chains may become more rigid and as a result, conduction mechanism is supported by ion hopping. On the other hand, at high temperatures, conductivity may be assisted thermally (Latif et al., 2006). That is, ions are energetically rich at high temperatures and so they can contribute for conductivity via hopping among vacant sites.

\section{DC polarization test}

Current variation through the cell with time (DC polarization graph) is shown in Fig.4.

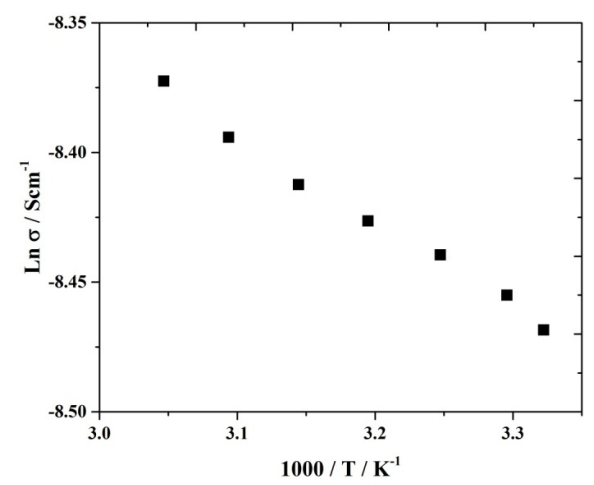

Figure 3: Variation of the conductivity with the temperature. 


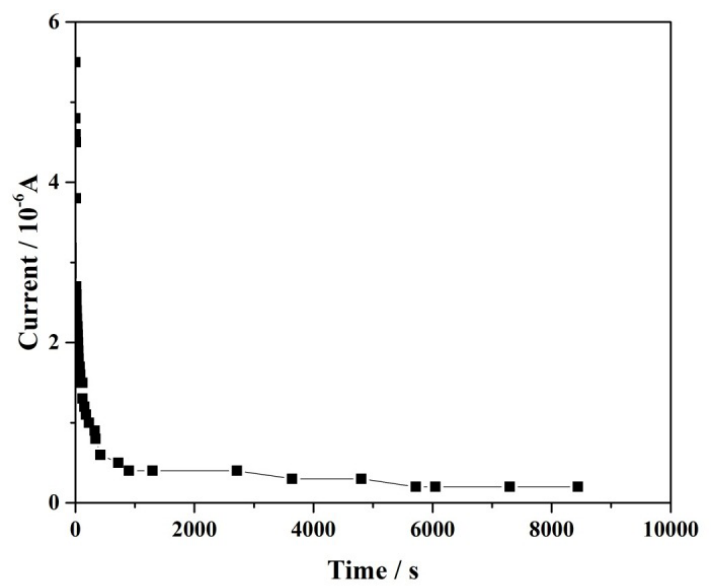

Figure 4: DC polarization graph obtained for the configuration, SS / NR based electrolyte / SS (SS: stainless steel electrodes).

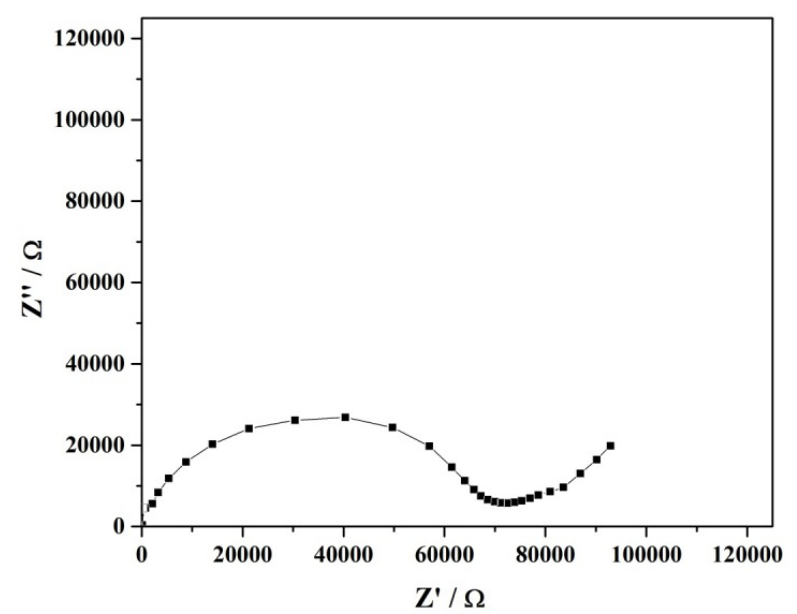

Figure 5: Nyquist plot of the cell, Mg / NR based electrolyte / graphite taken at the room temperature.

It can see in the DC polarization curve, an abrupt drop of current followed by a steady current. This is an indication for the ionic nature of the sample. Ionic nature of methyl grafted natural rubber samples have been reported by Yap et al [Yap et al., 2011]. Ionic transference number, $t_{i}$ was calculated using the equation, $t_{i}=\left(I_{t} I_{s}\right) / I_{t}$

Here, $I_{t}$ is the total current due to ions and electrons and $I_{s}$ is the steady current due to electrons (Pandey et al., 2011).

$t_{i}$ was found to be 0.96 . This well confirms the predominant ionic nature of the electrolyte.

\section{Evaluation of cell performance}

$\mathrm{V}_{\mathrm{OC}}$ of the cell in the configuration, $\mathrm{Mg} / \mathrm{NR}$ based electrolyte / graphite electrode was about 1.50 V. Fig.5 shows the nyquist plot of the cell. In general, there are two semicircles at high and middle frequency regions and a spike in the low frequency region in a nyquist plot of a cell. The high frequency semi circle represents the bulk electrolyte and the other semi circle shows the electrode features. The spike is a representation for capacitive properties. In the resulted nyquist plot, the high frequency semi circle is absent possibly due to unavailability of required high frequency values. Second semi circle is not disturbed very much. If some problems are present in the electrode as well as at the electrode/electrolyte interface, the correct shape of the semi circle is not present.

The drop of current in the discharge curve in Figure 6 is seemed to be steep. This happens when the cell discharges quickly. That is the constant load applied across the cell is quite small and hence, it discharges quickly. This can be controlled by using a higher load. The discharge capacity was determined by integrating the curve and it resulted a value of $5.32 \times 10^{-3} \mathrm{~A} \mathrm{~h} \mathrm{~g}^{-1}$.

Figure 7 shows the cyclic voltammogrammes obtained for several continuous cycles.

Cyclic voltammogrammes in Figure 7 follow the same pattern. This confirms the fact that there are no any parasitic reactions going on inside the cell during continuous charge-discharge process. All the curves in the cyclic voltammogramme show nearly mirror images around the origin. This proves that charge discharge processes are taking place efficiently. If there were some irreversible reactions, those processes are not identical to each other. As per our literature survey, only few have investigated natural rubber electrolyte based cells. Those are also limited to $\mathrm{Li}$ based cells and to a handful of characterization techniques (Tian et al., 2015, Mohamed et al., 2008). Further studies are in progress to improve the properties. 


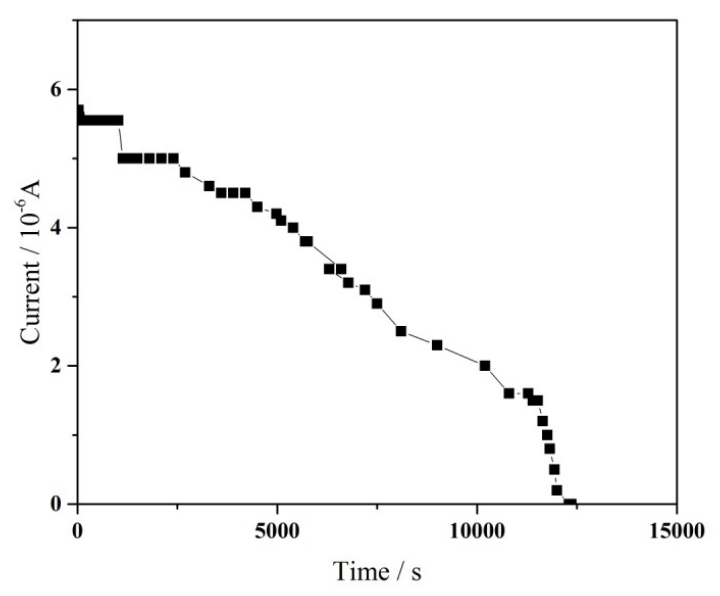

Figure 6: Constant load discharge characteristics of the cell $($ constant load $=100 \mathrm{~K} \Omega$ ).

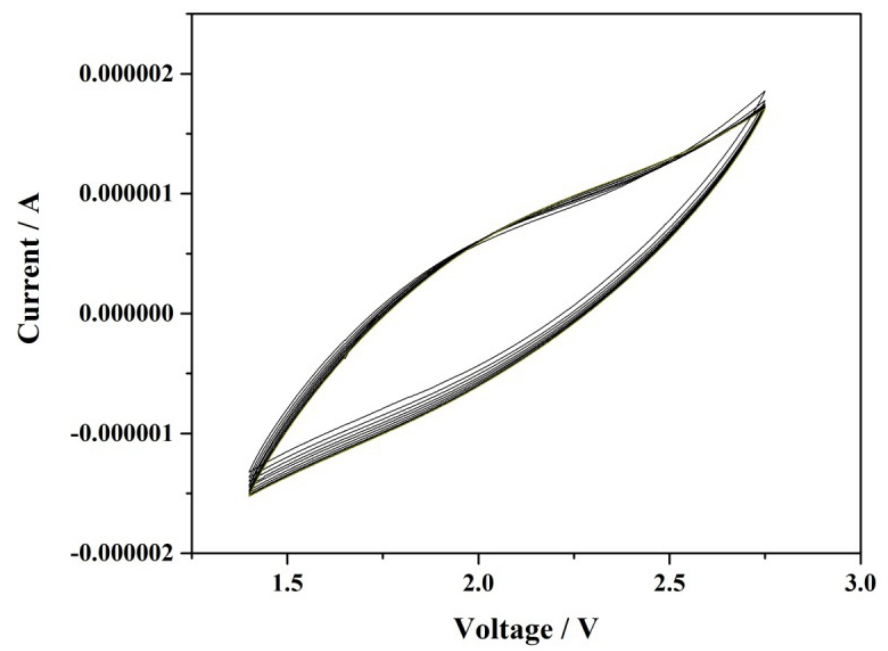

Figure 7: Cyclic Voltammogrammes of the cell obtained at the scan rate of $5 \mathrm{mV} / \mathrm{s}$.

\section{CONCLUSION}

$\mathrm{NR}$ is a viable substitute for commercially available polymers in preparing polymer electrolytes. Polymer electrolytes were successfully prepared with NR, MgTF and EC. The composition that had the highest conductivity of $2.83 \times 10^{-4} \mathrm{~S} \mathrm{~cm}^{-1}$ was $\left.63 \mathrm{MG} 49: 27 \mathrm{Mg}\left(\mathrm{CF}_{3} \mathrm{SO}_{3}\right)_{2}\right)$ : $10 \mathrm{EC}$ (by weight basis). Electrolyte is having a higher ionic contribution to the conductivity. The cell of the configuration, $\mathrm{Mg} / \mathrm{NR}$ based electrolyte / graphite exhibited a $\mathrm{V}_{\mathrm{OC}}$ of about $1.50 \mathrm{~V}$.

\section{ACKNOWLEDGEMENT}

Associated Specialty Rubbers (PVT) Ltd, Undugoda, Sri Lanka and Bogala Graphite Lanka (PVT) Ltd, Sri Lanka are highly acknowledged for providing samples. This work was supported by National Research Council, Sri Lanka (NRC 17-006) and Wayamba University of Sri Lanka (SRHDC / RP / 04 / 17/01).

\section{REFERENCES}

Agnohorty, S.A., Nidhi, S., Pradeep, P. and Sekhon, S.S.
(2000) $\mathrm{Li}^{+}$conducting gel electrolyte for electrochromic windows. Solid State Ionics 139: 573-576.

Ahmad, A., Rahman, M.Y.A., Harun, H., Suait, M.S. and Yarmo, M.A. (2012) Preparation and characterization of $49 \%$ P(MMA) grafted natural rubber (MG 49) Stannum (IV) oxide $\left(\mathrm{SnO}_{2}\right)$ - Li salt based composite polymer electrolytes. International Journal of Electrochemical Society 7: 8309-8325.

Ahmad, A., Rahman, M.Y.A., Low, S.P. and Hamzah, H. (2011) Effect of $\mathrm{LiBF}_{4}$ salt concentration on the properties of plasticized $\mathrm{MG} 49-\mathrm{TiO}_{2}$ based nano composite polymer electrolyte. SRN Materials Science 2011: 1-8.

Ali, A.M.M., Yahya, M.Z.M., Bahron, H. and Subban, R.H.Y. (2006) Electrochemical studies on polymer electrolytes based on poly(methyl methacrylate)grafted natural rubber for lithium polymer battery. Ionics 12: 303-307.

Borowski, J., Borowski, T. (2013) Receiving and the Capacitive Profile of the Capacitors Arrangements on the Base of Natural Rubber with the Addition of $\mathrm{SrCl}_{2}$ or $\mathrm{ZnCl}_{2}$ and the Active Carbon. International Letters 
of Chemistry, Physics and Astronomy 9: 9-14.

Gunasekaran, S., Natarajan, R.K. and Kala, A. (2007) FTIR spectra and mechanical strength analysis of some selected rubber derivatives. Spectrochimica Acta 68: 323-330.

Kamisan, A.S., Kudin, T.I.T., Ali, A.M.M. and Yahya, M.Z.M. (2009) Gel polymer electrolyte based on methyl grafted natural rubber for proton batteries. Material Research Innovations 13/3: 263-265.

Khoon, L.T., Ataollahi, N., Hassen, N.H. and Ahmad, A. (2016) Studies of porous solid polymeric electrolytes based on poly(vinylidenefluoride) and poly(methyl methacrylate) grafted natural rubber for applications in electrochemical devices. Journal of Solid State Electrochemistry 20/1: 203-213.

Latif, F., Aziz, M., Katun, N., Ali, A.M.M. and Yahya, M.Z. (2006) The role and impact of rubber in poly(methyl methacrylate)/lithium triflate electrolyte. Journal of Power Sources 159: 1401-1404.

Low, S.P., Ahmad, A. and Rahman, M.Y.A. (2010) Effect of ethylene carbonate plasticizer and $\mathrm{TiO}_{2}$ nanoparticles on $49 \%$ poly(methyl methacrylate) grafted natural rubber-based polymer electrolyte. Ionics 16:821- 826.

Mohamed, S.N., Johari, N.A., Ali, A.M.M., Harun, M.K. and Yahya, M.Z.A. (2008) Electrochemical studies on epoxidised natural rubber based gel polymer electrolyte for lithium air cells. Journal of Power Sources 183: 351-354.

Noor, S.A.M., Ahmad, A., Talib, I.A. and Rahman, M.Y.A. (2010) Morphology, chemical interaction, and conductivity of a PEO-ENR50 based on solid polymer electrolyte. Ionics 16: 161-170.

Noor, S.A.M., Ahmad, A., Rahman, M.Y.A. and Talib, I.A. (2010) Solid polymeric electrolyte of poly(ethylene) oxide $-50 \%$ epoxidised natural rubber - lithium triflate (PEO-ENR $50-\mathrm{LiCF}_{3} \mathrm{SO}_{3}$ ). Natural Sciences 2/3:190196.

Pandey, G.P., Agrawal, S.C. and Hashmi, S.A. (2011) Performance studies on composite gel polymer electrolytes for rechargeable magnesium battery application. Journal of Physics and Chemistry 72: 1408-1413.

TianKhoon, L., Hassan, N.H., Rahman, M.Y.A., Vedarajan, R., Matsumi, N. and Ahmad, A. (2015) One pot synthesis nano hybrid $\mathrm{ZrO}_{2}-\mathrm{TiO}_{2}$ fillers in $49 \%$ poly(methyl methacrylate)grafted natural rubber (MG 49) based nano composite polymer electrolyte for lithium ion battery application. Solid State Ionics 276: 72-79.

Yap, K.S., Teo, L.P., Sim, L.M.N., Majid, S.R. and Arof, A.K. (2011) Plasticized polymer electrolytes based on PMMA grafted natural rubber - $\mathrm{LiCF}_{3} \mathrm{SO}_{3}-\mathrm{PEG} 200$. Material Research Innovations 15: 34-38.

Yusoff, S.N.H.M., Sim, L.H., Chan, C.H., Aziz, S.S.S.A., Mahmud, Z.S. and Hairi, H.M. (2015) Studies on thermal and conductivity of modified natural rubber. Journal of Advanced Research in Material Science 12/1: 1-11. 